Military Technical College Kobry El-Kobbah, Cairo, Egypt

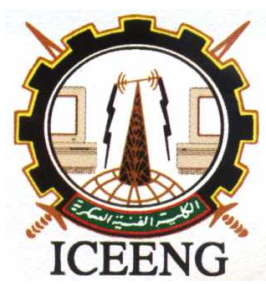

\author{
$6^{\text {th }}$ International Conference \\ on Electrical Engineering \\ ICEENG 2008
}

\title{
A new method for load balancing and power factor correction in 12- phase (multi-phase) load circuits
}

$$
\text { By }
$$
Zakir Husain *
R. K. Singh **
S. N. Tiwari $* * *$

\section{Abstract:}

Multi-phase loads, employing more than three phases, specially in the form of inverter fed induction motor drives suited to high power and specialized applications, are receiving growing attention in the literature. This multi-phase source for such drive application may be derived from transformer connection ( 3 phase to 12 phase) or by DC link 12-phase inverters. These sources will face the problem of unbalance, harmonic distortion and poor power factor operation. In view of these developments, this paper deals with the supply side load balancing and power factor correction in such load circuits. The proposed compensation scheme uses the shunt current source compensation whose instantaneous values are determined by the instantaneous symmetrical component theory. The compensation scheme developed in the paper is based on principle reported and is tested for its validity on 12-phase (12-wire \& 13wire) circuits through extensive simulations for unbalanced loading and phase outages. The simulation results of the compensation theory and the ideal compensator verify the compensation method.

* Department of Elec. Eng., N.I.T. Hamirpur (H.P.) INDIA

** Department of Elec. Eng., M.N.N.I.T, Allahabad, INDIA

*** LDC Institute of Technical Studies, Allahabad, INDIA 